ARTICLE

Received 27 Mar 2013 | Accepted 12 Jun 2013 | Published 11 Jul 2013 DOl: 10.1038/ncomms3141

\title{
Chemical synthesis of lactic acid from cellulose catalysed by lead(II) ions in water
}

Yanliang Wang ${ }^{1, \star}$, Weiping Deng ${ }^{2, \star}$, Binju Wang ${ }^{1, \star}$, Qinghong Zhang ${ }^{1,2}$, Xiaoyue Wan ${ }^{1}$, Zhenchen Tang ${ }^{1}$, Ye Wang ${ }^{1,2}$, Chun Zhu', Zexing Cao', Guichang Wang ${ }^{3}$ \& Huilin Wan ${ }^{1,2}$

The direct transformation of cellulose, which is the main component of lignocellulosic biomass, into building-block chemicals is the key to establishing biomass-based sustainable chemical processes. Only limited successes have been achieved for such transformations under mild conditions. Here we report the simple and efficient chemocatalytic conversion of cellulose in water in the presence of dilute lead(II) ions, into lactic acid, which is a high-value chemical used for the production of fine chemicals and biodegradable plastics. The lactic acid yield from microcrystalline cellulose and several lignocellulose-based raw biomasses is $>60 \%$ at $463 \mathrm{~K}$. Both theoretical and experimental studies suggest that lead(II) in combination with water catalyses a series of cascading steps for lactic acid formation, including the isomerization of glucose formed via the hydrolysis of cellulose into fructose, the selective cleavage of the $\mathrm{C} 3-\mathrm{C} 4$ bond of fructose to trioses and the selective conversion of trioses into lactic acid.

\footnotetext{
${ }^{1}$ State Key Laboratory of Physical Chemistry of Solid Surfaces, Collaborative Innovation Center of Chemistry for Energy Materials, College of Chemistry and Chemical Engineering, Xiamen University, Xiamen 361005, China. ${ }^{2}$ National Engineering Laboratory for Green Chemical Productions of Alcohols, Ethers and Esters, College of Chemistry and Chemical Engineering, Xiamen University, Xiamen 361005, China. ${ }^{3}$ Department of Chemistry and the Tianjin Key Lab of Metal and Molecule-based Material Chemistry, Nankai University, Tianjin 300071, China. ${ }^{\star}$ These authors contributed equally to this work. Correspondence and requests for materials should be addressed to Y.W. (email: wangye@xmu.edu.cn).
} 
T here is a strong incentive to produce chemicals and fuels from renewable biomass resources to reduce the reliance on diminishing fossil resources ${ }^{1,2}$. Although the conventional biological process, typically the fermentation of biomass-based carbohydrates, possesses some advantages, a chemocatalytic process provides opportunities to increase the process efficiency because the catalysts and the operation conditions can be readily engineered and optimized. Furthermore, chemocatalysis may allow the direct transformation of biomass feedstocks other than monosaccharides or oligosaccharides into chemicals in a one-pot process by designing multifunctional catalytic systems. Many studies have been devoted to establishing the basis for the conversion of biomassbased carbohydrates into liquid fuels and chemicals via platform molecules, such as 5 -hydroxymethylfurfural $(\mathrm{HMF})^{3-6}$. However, less attention has been paid to developing chemocatalytic routes for the production of building-block chemicals directly from biomass ${ }^{7-10}$.

Lignocellulosic biomass is expected to be the most promising renewable biomass feedstock owing to its wide abundance ${ }^{1}$. The efficient transformation of cellulose, the main component of lignocellulosic biomass, into chemicals is essential for the utilization of lignocellulosic biomass as a chemical feedstock. The high-temperature gasification of cellulose to synthesis gas, which can be used for the synthesis of methanol or hydrocarbons, is limited by a high-energy requirement and low selectivity ${ }^{11}$. The hydrolysis of cellulose by cellulase occurs at ambient temperatures ${ }^{12}$, but this high-cost process is currently impractical for large-scale production of glucose. The transformation of cellulose in ionic liquids, which can dissolve cellulose, has received much attention ${ }^{13}$, but ionic liquids are expensive. The chemocatalytic conversion of cellulose into chemicals in water under mild conditions is an ideal but highly challenging route ${ }^{14,15}$. Moderate success has been achieved for the hydrogenolysis of cellulose into polyols (for example, ethylene and propylene glycols of commercial interest $)^{16-18}$. However, the consumption of hydrogen is required in these reactions. There are few systems capable of catalysing the transformation of cellulose directly into high-value chemicals in water without the consumption of hydrogen.

Lactic acid is an important building-block chemical widely used in the food, pharmaceutical, cosmetic and chemical industries. In particular, lactic acid has received much attention as a monomer for the production of biodegradable plastics ${ }^{8-10,19,20}$. Currently, lactic acid is primarily produced by the fermentation of glucose. However, this biological process is not applicable directly to cellulose, and the pre-hydrolysis of cellulose to glucose is required. Due to the growing demand for lactic acid, this biocatalytic route may have important roles in industry. At the same time, the development of novel chemocatalytic processes for the production of lactic acid from biomass has also attracted much attention in recent years ${ }^{21}$. The chemical conversion of carbohydrates to lactate salts with low yields $(<30 \%)$ does proceed in alkaline medium (for example, $\mathrm{NaOH}$ ) at temperatures of $\sim 573 \mathrm{~K}^{22}$. The harsh reaction conditions, limited yields and consumption of a stoichiometric amount of base hinder the commercialization of this process. Recent reports disclosed that $\mathrm{Sn}(\mathrm{IV})$-beta and $\mathrm{Sn}(\mathrm{IV})$ grafted on a mesoporous carbon-silica composite could catalyse the conversion of carbohydrates, such as glucose, fructose and sucrose, in an alcohol medium into alkyl lactate ${ }^{8,9}$. Although promising, these $\mathrm{Sn}(\mathrm{IV})$-based catalysts are limited to the transformation of mono or disaccharides.

Herein, we report for the first time that lactic acid can be directly produced from cellulose with high efficiency by a simple chemocatalytic system. The system is composed of a diluted metal ion (i.e., $\mathrm{Pb}(\mathrm{II})$ ) in water. The chemistry of this system has been clarified through comprehensive theoretical studies as well as experimental validation. We have demonstrated that simple $\mathrm{Pb}(\mathrm{II})$ in combination with water can accomplish complicated cascade reactions for the transformation of cellulose to lactic acid.

\section{Results}

Catalytic performance of $\mathrm{Pb}(\mathrm{II})$ for cellulose conversion. We discovered that cellulose could be converted directly into lactic acid in hot water by simply adding a metal cation. Figure 1 shows that an outstanding yield of lactic acid $(68 \%)$ has been attained in the presence of diluted $\mathrm{Pb}(\mathrm{II})$ with a concentration of $7 \mathrm{mmol} \mathrm{dm}{ }^{-3}(\mathrm{mM})$ for the conversion of ball-milled cellulose (crystallinity $=33 \%$, Supplementary Fig. S1) after $4 \mathrm{~h}$ at $463 \mathrm{~K}$. In addition, glucose, fructose and organic acids, such as glycolic acid and levulinic acid, were also formed but with lower yields (Supplementary Note S1). Other cations, including $\mathrm{Al}(\mathrm{III})$, $\mathrm{Bi}(\mathrm{III}), \mathrm{In}(\mathrm{III})$ and $\mathrm{Zn}(\mathrm{II})$, with $\mathrm{d}^{10}$ or $\mathrm{d}^{10} \mathrm{~s}^{2}$ electronic configuration also catalysed the conversion of the ball-milled cellulose into lactic acid with yields of $>20 \%$. In most cases, metal nitrates were employed in our experiments, and we confirmed that the counter anions did not exert significant influences on the catalytic performance (Supplementary Table S1).

We investigated the effect of the concentration of $\mathrm{Pb}(\mathrm{II})$ on the transformation of the ball-milled cellulose. In the absence of $\mathrm{Pb}(\mathrm{II})$, the ball-milled cellulose could also be converted in water at $463 \mathrm{~K}$ to yield glucose and HMF as the main products. No lactic acid was formed. We speculate that the $\mathrm{H}_{3} \mathrm{O}^{+}$ions, which are reversibly generated in hot water owing to the increased ionization constant of water at higher temperatures ${ }^{23,24}$, can catalyse the hydrolysis of the ball-milled cellulose to glucose. HMF can be formed by the dehydration of fructose ${ }^{3,4,25}$, which is an isomer of glucose. The presence of $\mathrm{Pb}$ (II) decreased the yields of glucose and HMF, and resulted in the formation of lactic acid (Supplementary Fig. S2). The yield of lactic acid increased steeply with the concentration of $\mathrm{Pb}$ (II) and reached $\sim 50 \%$ at a $\mathrm{Pb}$ (II) concentration of $0.7 \mathrm{mM}$. The turnover number (TON) for the lactic acid formation evaluated at this concentration of $\mathrm{Pb}$ (II) was 22. Further increases in the concentration of $\mathrm{Pb}(\mathrm{II})$ slightly increased the yield of lactic acid, and a plateau of $\sim 70 \%$ was attained.

We performed the conversion of cellulose with different quantities in $100 \mathrm{ml}$ water. A lactic acid yield of $55 \%$ could be obtained for a cellulose quantity of $2.5 \mathrm{~g}$ (Supplementary Table S2). The molar ratio of the glucose unit in cellulose to $\mathrm{Pb}(\mathrm{II})$ was 25 at this point providing a TON of 14. An increase in the molar

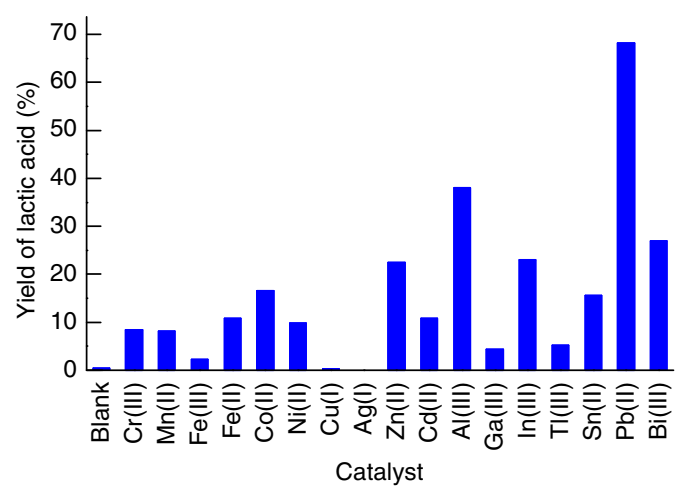

Figure 1 | Catalytic performance of metal cations for the conversion of cellulose to lactic acid. Reaction conditions: metal cation, $0.14 \mathrm{mmol}$; ball-milled cellulose, $0.10 \mathrm{~g}$ (glucose unit: $0.62 \mathrm{mmol}$ ); $\mathrm{N}_{2}, 3 \mathrm{MPa} ; \mathrm{H}_{2} \mathrm{O}$, $20 \mathrm{ml}$; temperature, $463 \mathrm{~K}$; reaction time, $4 \mathrm{~h}$. 
ratio of the glucose unit in cellulose to $\mathrm{Pb}$ (II) to 300 by decreasing the amount of $\mathrm{Pb}(\mathrm{II})$ provided a lactic acid yield of $34 \%$ and a TON of 102. However, a further increase in the quantity of cellulose to $5.0 \mathrm{~g}$ significantly decreased the yield of lactic acid owing to poor mechanical agitation and the formation of humin possibly via the dehydration of carbohydrate intermediates resulting from the increased Brønsted acidity of the solution.

As expected, the conversion of microcrystalline cellulose (crystallinity $=85 \%$ ) became more difficult. In the absence of $\mathrm{Pb}(\mathrm{II}), \mathrm{HMF}$ and glucose were also obtained as the main products, but their yields were only $\sim 9$ and $4 \%$ even after $15 \mathrm{~h}$ of reaction at $463 \mathrm{~K}$ (Supplementary Fig. S3). The presence of $\mathrm{Pb}(\mathrm{II})$ accelerated the conversion of microcrystalline cellulose, and a lactic acid yield of $62 \%$ was attained after $15 \mathrm{~h}$ of reaction at $463 \mathrm{~K}$. Therefore, $\mathrm{Pb}(\mathrm{II})$ ions had significant roles both in directing the reaction towards the formation of lactic acid and in enhancing the conversion of microcrystalline cellulose. We further clarified that the lactic acid product enhanced the conversion of cellulose. The intentional addition of lactic acid into the reaction system significantly shortened the time required to achieve a lactic acid yield of $\sim 60 \%$ (Supplementary Fig. S4), which clearly indicated the autocatalytic function of lactic acid $\left(\mathrm{p} K_{\mathrm{a}}\right.$ of 3.66 at $\left.298 \mathrm{~K}\right)$ in the hydrolysis of cellulose.

Conversions of other biomasses and raw biomasses. The present catalytic system is applicable to the transformation of other biomasses, such as starch and inulin, which are polymers of glucose and (fructose + glucose) (Supplementary Table S3). The yields of lactic acid from starch and inulin reached $68 \%$ and $73 \%$, respectively, after $2 \mathrm{~h}$ of reaction at $463 \mathrm{~K}$ (Supplementary Table S4). We also examined the direct transformations of several lignocellulose-based non-purified raw biomasses including sugar bagasse, couch grass and bran (see Supplementary Table S3 for compositions) in the presence of $\mathrm{Pb}(\mathrm{II})$ and obtained lactic acid yields of $\geq 66 \%$ based on the amount of $\mathrm{C}_{6}$ and $\mathrm{C}_{5}$ monosaccharide units contained in these biomasses (Supplementary Table S4 and Supplementary Note S2). For the conversions of inulin, starch and the raw biomasses (sugar bagasse, couch grass
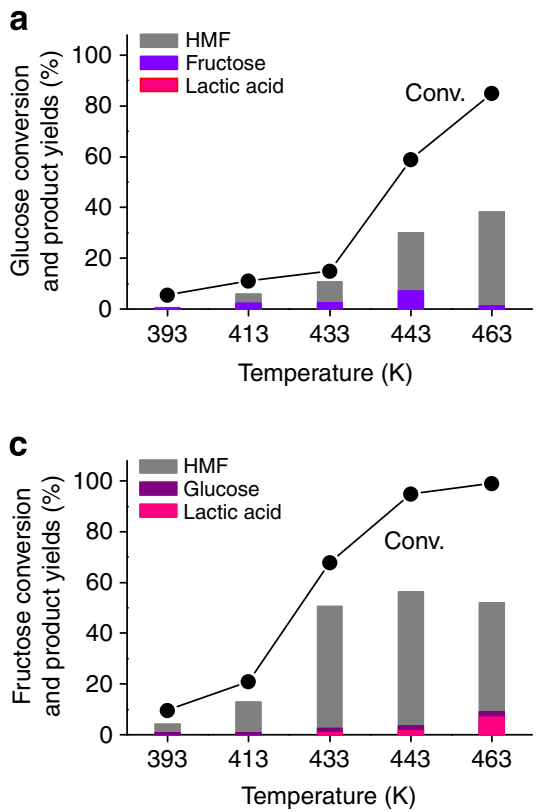

and bran), the use of a larger quantity $(2.5 \mathrm{~g}$ in $100 \mathrm{ml}$ water $)$ resulted in lactic acid yields of $\geq 41 \%$ based on the amount of $\mathrm{C}_{6}$ and $\mathrm{C}_{5}$ monosaccharide units contained in these biomasses (Supplementary Table S5). In addition, we performed the separation and recovery of $\mathrm{Pb}(\mathrm{II})$ from the reaction system and found that all of the $\mathrm{Pb}$ (II) ions in the reaction solution could be recovered simply by using a cationic exchanging resin (Amberlite IR-120 resin) (Supplementary Note S3).

Reaction mechanism and catalytic function of $\mathrm{Pb}$ (II). To gain insights into the reaction pathways, we performed the conversion of glucose and fructose, which are two possible monosaccharide intermediates. In the absence of $\mathrm{Pb}(\mathrm{II})$, HMF was the main product in both cases (Fig. 2a,c). The presence of $\mathrm{Pb}(\mathrm{II})$ increased the conversion of either glucose or fructose, especially at lower temperatures $(\leq 433 \mathrm{~K})$, and switched the main product from HMF to lactic acid (Fig. 2b and d). The lactic acid yields reached $71 \%$ and $74 \%$ for the conversions of glucose and fructose at 443 and $463 \mathrm{~K}$, respectively. $\mathrm{Pb}$ (II) also enhanced the conversion of glucose to fructose at $\leq 433 \mathrm{~K}$ (Fig. 2b). A detailed time-course analysis for the conversion of glucose at $423 \mathrm{~K}$ in the presence of $\mathrm{Pb}(\mathrm{II})$ indicated that fructose was the intermediate for the conversion of glucose to lactic acid (Supplementary Fig. S5). These results suggest that the reaction proceeds via the reaction pathways shown in Fig. 3. $\mathrm{Pb}$ (II) catalyses both the isomerization of glucose to fructose and the conversion of fructose to lactic acid.

We conducted theoretical computations for the conversion of glucose to lactic acid using a cluster-continuum model to elucidate the reaction mechanism and the catalytic function of $\mathrm{Pb}$ (II). The computational approach adopted in the current study has been verified to be practicable for chemical reactions in aqueous solutions $s^{26,27}$. Our computational results are displayed in Fig. 4 and Table 1, and the details are summarized in the Supplementary Information (Supplementary Figs S6-S33 and Supplementary Tables S6-S9). In brief, the conversion of glucose to lactic acid can be roughly divided into the following three stages: (i) the isomerization of glucose to fructose $(\mathbf{1} \rightarrow \mathbf{3})$, (ii) the retro-aldol fragmentation of fructose producing two $\mathrm{C}_{3}$
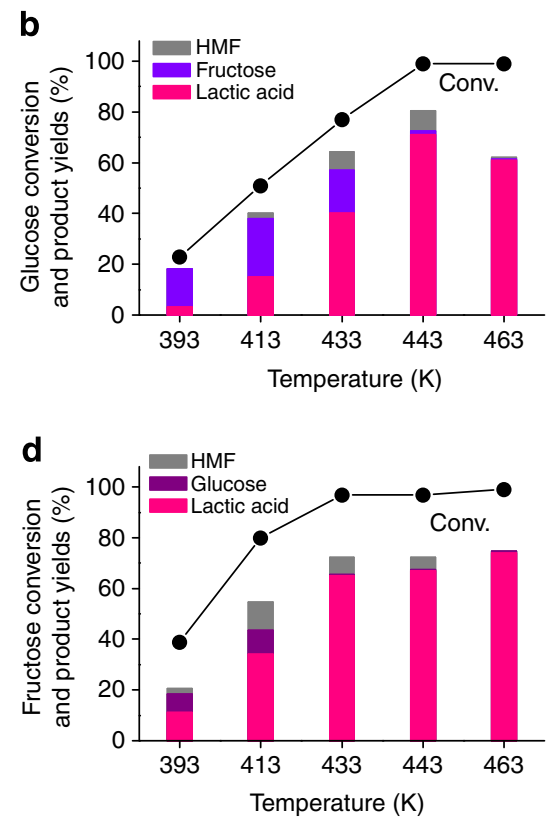

Figure 2 I Conversion of glucose and fructose in the absence and presence of Pb(II). (a) Glucose conversion in the absence of Pb(II). (b) Glucose

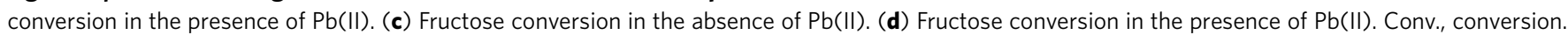
Reaction conditions: $\mathrm{Pb}(\mathrm{II}), 0.14 \mathrm{mmol}$; glucose, $0.51 \mathrm{mmol}$; fructose, $0.56 \mathrm{mmol} ; \mathrm{H}_{2} \mathrm{O}, 20 \mathrm{ml}$; $\mathrm{N}_{2}, 3 \mathrm{MPa}$; reaction time, $2 \mathrm{~h}$. 


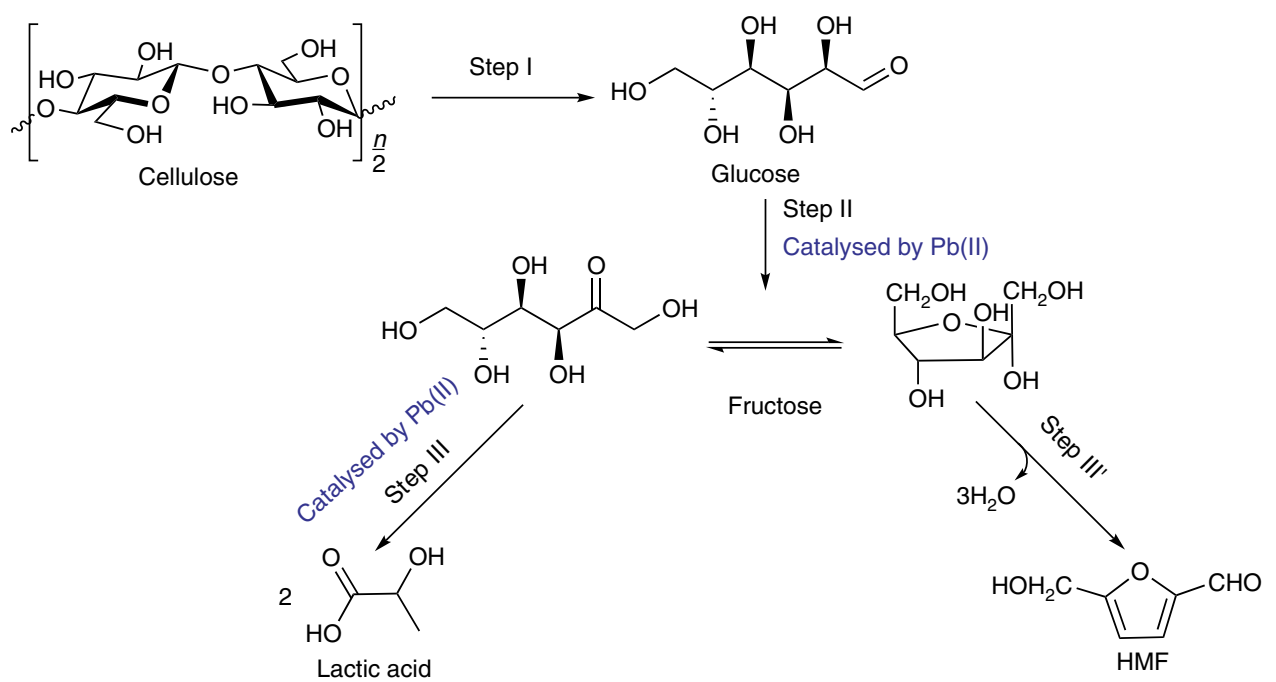

Figure 3 | Reaction pathways. Reaction pathways for the conversion of cellulose into lactic acid and $\mathrm{HMF}$ in the presence and absence of $\mathrm{Pb}(\mathrm{II})$ in water.

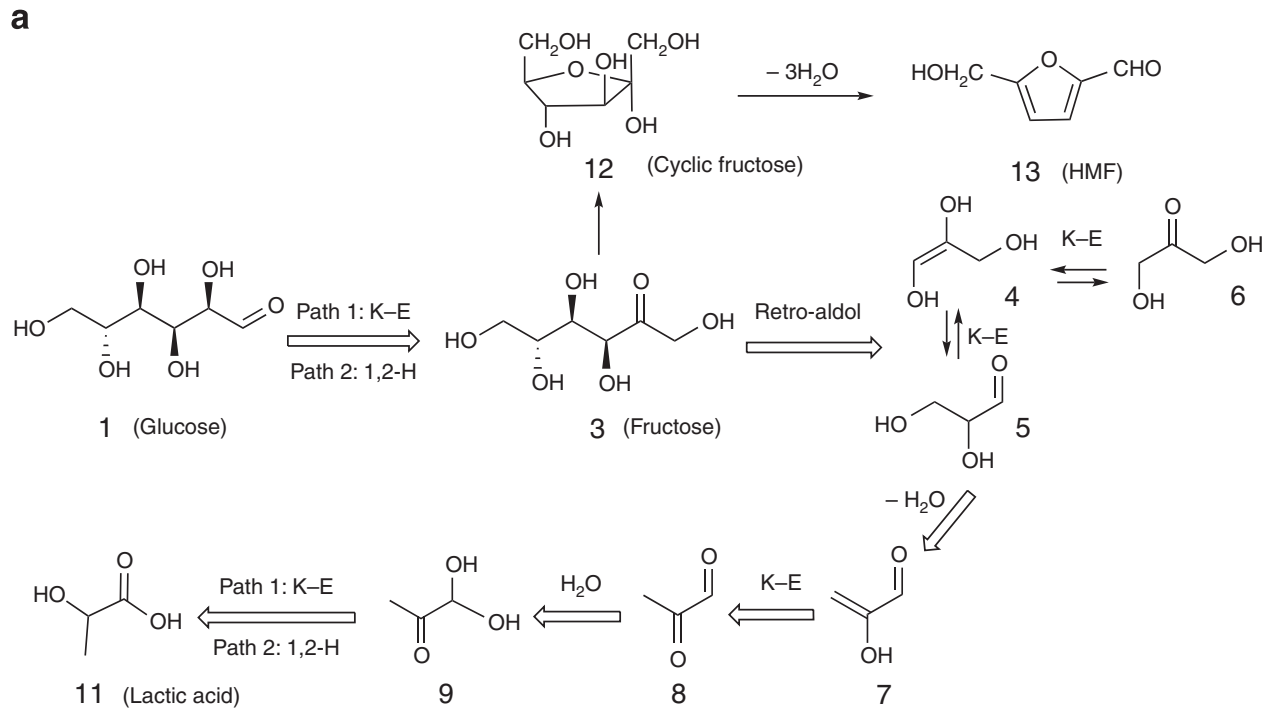

b<smiles>[R]C1=C([R])O[Pb]([O])O1</smiles>

C

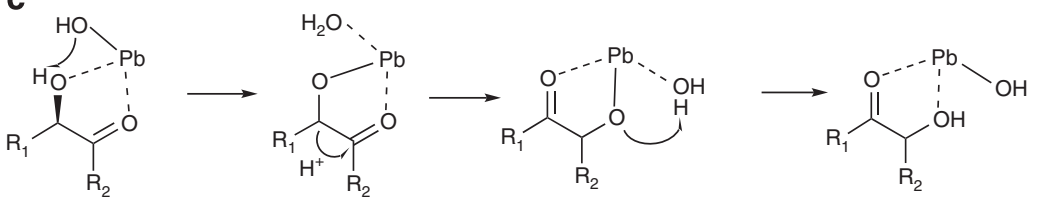

Figure 4 | Reaction mechanism. (a) Proposed reaction mechanism based on theoretical computations for the conversion of glucose to lactic acid in water. (b) Path 1 for the isomerization of glucose or trioses: K-E (i.e., consecutive keto-enol tautomerization) via the Pb(II) model. (c) Path 2 for the isomerization of glucose or trioses: 1,2-H (i.e., 1,2-hydride shift) via the $\mathrm{Pb}(\mathrm{II})-\mathrm{OH}$ model. The calculated activation Gibbs energies and Gibbs free energies for the key steps are displayed in Table 1.

intermediates or trioses $(\mathbf{3} \rightarrow \mathbf{4}+\mathbf{5})$ and (iii) the isomerization of these trioses $(\mathbf{4} \leftrightarrow \mathbf{5} \rightarrow \mathbf{1 1})$ into lactic acid (Fig. 4).

For the isomerization of glucose to fructose, we performed computations for two possible paths (that is, the consecutive keto-enol tautomerization (denoted as K-E) and the 1,2-hydride shift (denoted as 1,2-H) paths) ${ }^{28-30}$. The activation Gibbs energies $\left(\Delta G^{\neq}\right)$obtained for these two paths were 24.1 and $32.8 \mathrm{kcal} \mathrm{mol}^{-1}$ in aqueous solution without the $\mathrm{Pb}$ (II) catalyst (Supplementary Table S6 and Supplementary Fig. S10). This result suggests that the consecutive keto-enol tautomerization 


\begin{tabular}{|c|c|c|c|}
\hline \multirow[b]{2}{*}{$\begin{array}{l}\text { Reaction } \\
\text { step }^{\star}\end{array}$} & \multirow[b]{2}{*}{$\begin{array}{l}\text { Non-catalytic } \\
\text { route }^{\dagger}\end{array}$} & \multicolumn{2}{|c|}{ Catalytic route ${ }^{\dagger}$} \\
\hline & & $\begin{array}{l}\text { Catalysed } \\
\text { by } \mathrm{Pb}(\mathrm{II})\end{array}$ & $\begin{array}{l}\text { Catalysed } \\
\text { by } \mathrm{Pb}(\mathrm{II})-\mathrm{OH}\end{array}$ \\
\hline $1 \rightarrow 3$ & $\begin{array}{l}\Delta G^{\neq}=24.1 \\
\Delta G_{r}=-3.7\end{array}$ & $\begin{array}{l}\Delta G^{\neq}=22.0 \\
\Delta G_{r}=4.3\end{array}$ & $\begin{array}{l}\Delta G^{\neq}=19.5 \\
\Delta G_{r}=-11.0\end{array}$ \\
\hline $3 \rightarrow 4+5$ & $\begin{array}{l}\Delta G^{\neq}=32.8 \\
\Delta G_{r}=12.8\end{array}$ & $\begin{array}{l}\Delta G^{\neq}=22.4 \\
\Delta G_{r}=18.6\end{array}$ & $\begin{array}{l}\Delta G^{\neq}=24.4 \\
\Delta G_{r}=8.2\end{array}$ \\
\hline 5 & $\begin{array}{l}\Delta G^{\neq}=25.9 \\
\Delta G_{r}=-9.3\end{array}$ & $\begin{array}{l}\Delta G^{\neq}=28.8 \\
\Delta G_{r}=-3.5\end{array}$ & $\begin{array}{l}\Delta G^{\neq}=22.4 \\
\Delta G_{r}=-4.2\end{array}$ \\
\hline $7 \rightarrow 9$ & $\begin{array}{l}\Delta G^{\neq}=18.7 \\
\Delta G_{r}=-2.8\end{array}$ & Uncalculated & Uncalculated \\
\hline $9 \rightarrow 11$ & $\begin{array}{l}\Delta G^{\neq}=32.1 \\
\Delta G_{r}=-11.6\end{array}$ & $\begin{array}{l}\Delta G^{\neq}=23.5 \\
\Delta G_{r}=9.1\end{array}$ & $\begin{array}{l}\Delta G^{\neq}=23.2 \\
\Delta G_{r}=-15.1\end{array}$ \\
\hline $\begin{array}{l}\text { glucose to I } \\
\text { *See Fig. } 4 . \\
\text { reaction, res }\end{array}$ & $\Delta G^{\neq}$ar & ation Gibbs en & $\begin{array}{l}\text { in the conversi } \\
b(I I)-O H . \\
\text { Gibbs free ener. }\end{array}$ \\
\hline
\end{tabular}

path is more favourable in the non-catalytic reaction. The presence of $\mathrm{Pb}(\mathrm{II})$ decreased the activation Gibbs energy for this path to $22.0 \mathrm{kcal} \mathrm{mol}^{-1}$ (Supplementary Table S8). A Sn(IV)-OH species had been proposed to be responsible for the Sn-beta-catalysed isomerization of glucose to fructose ${ }^{29,30}$. Our computation provided a low energy barrier $\left(\Delta G^{\neq}=3.6 \mathrm{kcal} \mathrm{mol}^{-1}\right)$ for the transformation of $\mathrm{Pb}(\mathrm{II})$ to $\mathrm{Pb}$ (II)-OH in water (Supplementary Fig. S19). Many studies have demonstrated the formation of $\mathrm{Pb}(\mathrm{II})-\mathrm{OH}$ in an aqueous solution of $\mathrm{Pb}$ (II) (Supplementary Note $\mathrm{S} 4)^{31-34}$. Our experimental studies using Fourier-transform ion cyclotron resonance mass spectrometry, which is a very powerful technique for the structural determination of new compounds with ultra-high mass resolution and accuracy ${ }^{35,36}$, provided further evidence for the existence of the $\mathrm{Pb}(\mathrm{II})-\mathrm{OH}$ species in the $\mathrm{Pb}(\mathrm{II})$ aqueous solution (Supplementary Fig. S34). When $\mathrm{Pb}(\mathrm{II})-\mathrm{OH}$ is assumed to be the active species instead of $\mathrm{Pb}(\mathrm{II})$, the calculation indicates that the activation Gibbs energy for the 1,2-hydride shift path $\left(\Delta G^{\neq}=19.5 \mathrm{kcal} \mathrm{mol}^{-1}\right)$ is lower than that for the keto-enol tautomerization path $\left(\Delta G^{\neq}=22.0 \mathrm{kcal} \mathrm{mol}^{-1}\right)$ (Supplementary Fig. S24 and Supplementary Table S8). Using deuterium-labelled glucose (glucose-D2) as the substrate, we experimentally confirmed that the isomerization of glucose into fructose primarily proceeded via the 1,2-hydride shift mechanism in the presence of the lead catalyst (Supplementary Fig. S35). These results suggest the role of the $\mathrm{Pb}(\mathrm{II})-\mathrm{OH}$ species in the isomerization of glucose to fructose.

The conversion of the trioses formed from the cleavage of the $\mathrm{C}-\mathrm{C}$ bond of fructose undergoes several isomerization steps as well as dehydration and hydration to form lactic acid $(\mathbf{5} \rightarrow \mathbf{1 1})$. Our calculations suggest that the 1,2-hydride shift is also a preferential path for the isomerization of 1,1-dihydroxy-acetone to lactic acid $(\mathbf{9} \rightarrow \mathbf{1 1})$ (Supplementary Fig. S33), which is the most difficult step in the conversion of trioses to lactic acid.

In addition to the isomerization reactions, the retro-aldol fragmentation of fructose into trioses (that is, glyceraldehyde (5) and enediol intermediate (4)) is a crucial step. In the absence of $\mathrm{Pb}$ (II), our calculations indicate that the activation Gibbs energy for this step is $32.8 \mathrm{kcal} \mathrm{mol}^{-1}$ (Supplementary Fig. S11), which is a highly energy demanding step in the non-catalytic transformation of glucose to lactic acid (Table 1). In comparison with the retro-aldol fragmentation, the dehydration of fructose into HMF $(3 \rightarrow \mathbf{1 3})$ proceeds with a lower energy barrier in the absence of $\mathrm{Pb}$ (II) $\left(3 \rightarrow 12: \Delta G^{\neq}=22.0 \mathrm{kcal} \mathrm{mol}^{-1}, \mathbf{1 2} \rightarrow \mathbf{1 3}\right.$ :
$\Delta G^{\neq}=29.1 \mathrm{kcal} \mathrm{mol}^{-1}$; $\quad$ Supplementary $\quad$ Fig $\mathrm{S} 17$ and Supplementary Table S7). The presence of $\mathrm{Pb}$ (II) significantly reduces the activation Gibbs energy for the retro-aldol fragmentation from 32.8 to $22.4 \mathrm{kcal} \mathrm{mol}^{-1}$ (Supplementary Table S9). The activation Gibbs energy for this step increases slightly $\left(\Delta G^{\neq}=24.4 \mathrm{kcal} \mathrm{mol}^{-1}\right)$ when $\mathrm{Pb}(\mathrm{II})-\mathrm{OH}$ is assumed to be the active species (Supplementary Fig. S29). Therefore, it becomes quite clear that $\mathrm{Pb}$ (II) has a crucial role in the cleavage of the $\mathrm{C}-\mathrm{C}$ bond of fructose. Without $\mathrm{Pb}(\mathrm{II})$, the dehydration of fructose to HMF would preferentially proceed owing to the relatively lower energy barrier for the dehydration compared with that for the retro-aldol fragmentation.

Our tandem mass spectrometry studies provided experimental evidence for the catalytic function of $\mathrm{Pb}$ (II) in the retro-aldol reaction. In the mass (MS) and the tandem mass (MS/MS) spectra, we observed the species of the $\mathrm{Pb}$-fructose complex and the fragment formed via the cleavage of the $\mathrm{C} 3-\mathrm{C} 4$ bond in fructose coordinated to $\mathrm{Pb}$ (II) (Supplementary Fig. S36). Only the fragments from the dehydration of fructose were detected in the $\mathrm{MS}$ and the MS/MS spectra in the absence of $\mathrm{Pb}(\mathrm{II})$ (Supplementary Fig. S37).

Our computational results displayed in Table 1 reveal that the presence of $\mathrm{Pb}(\mathrm{II})$ also significantly decreases the activation barrier for reaction step $\mathbf{9} \rightarrow \mathbf{1 1}$, which is the most difficult step in the conversion of trioses to lactic acid. In addition, we performed experimental studies on the conversion of trioses (that is, glyceraldehyde (5), dihydroxyacetone (6) and pyruvaldehyde (8)) at $463 \mathrm{~K}$ in aqueous solutions. For the conversion of all of these trioses in the presence of $\mathrm{Pb}(\mathrm{II})$, lactic acid was produced with high yields ( $\geq 91 \%$ ), while the absence of $\mathrm{Pb}$ (II) led to significantly lower lactic acid yields $(\leq 18 \%)$ (Supplementary Table $\mathrm{S} 10$ ). This suggests that our $\mathrm{Pb}$ (II) catalyst also has a role in the conversion of trioses to lactic acid.

\section{Discussion}

We discovered a simple and highly efficient homogeneous catalyst for the direct transformation of cellulose into lactic acid in an aqueous solution. The system containing diluted $\mathrm{Pb}$ (II) in water not only catalyses the conversion of ball-milled cellulose, as well as glucose and fructose, to lactic acid with high yields ( $\sim 70 \%$ ) but also is efficient for the conversion of microcrystalline cellulose (lactic acid yield, $\sim 60 \%$ ). The system is also applicable to the transformation of lignocellulose-based raw biomasses without pretreatment. To the best of our knowledge, this is the first report to demonstrate the production of lactic acid with considerable yields $(>50 \%)$ from cellulose.

We have clarified that the chemistry of the present system involves multistep cascade reactions including the hydrolysis of cellulose to glucose, the isomerization of glucose to fructose, the retro-aldol fragmentation of fructose to trioses and the conversion of trioses to lactic acid. While the dehydration of fructose to HMF primarily occurs in the absence of $\mathrm{Pb}(\mathrm{II})$, the presence of $\mathrm{Pb}(\mathrm{II})$ shifts the main reaction route to the formation of lactic acid.

Our computational results agree well with the experimental findings and provide a basis for understanding the remarkable catalytic role of $\mathrm{Pb}(\mathrm{II})$. In particular, the presence of $\mathrm{Pb}(\mathrm{II})$ significantly decreases the activation barrier for the retro-aldol fragmentation of fructose changing the main reaction route from the formation of HMF to the formation of lactic acid. A detailed reaction path analysis reveals that the $\mathrm{C}-\mathrm{C}$ bond cleavage of fructose is triggered by the proton transfer from the $\mathrm{C} 4-\mathrm{OH}$ to $\mathrm{C} 2=\mathrm{O}$ (Supplementary Fig. S27). Our calculation suggests that the coordination of $\mathrm{Pb}(\mathrm{II})$ to the oxygen atoms of fructose increases the positive charges on the $\mathrm{H}$ atom of the $\mathrm{C} 4-\mathrm{OH}$ 
(Supplementary Figs S11, S27 and S28). This indicates that $\mathrm{Pb}(\mathrm{II})$ enhances the acidity of the $\mathrm{C} 4-\mathrm{OH}$, thereby facilitating the proton transfer and the $\mathrm{C}-\mathrm{C}$ bond cleavage in the retro-aldol reaction. In comparison with other metal ions, the larger size (radius of $\mathrm{Pb}(\mathrm{II})=119 \mathrm{pm}$ ) and closed shell of $\mathrm{Pb}(\mathrm{II})$ may lead to it being better coordinated by the oxygen atoms of fructose. This may allow $\mathrm{Pb}(\mathrm{II})$ to mediate the initial proton transfer more effectively in the above step. In addition, the lone electron pair $\left(6 \mathrm{~s}^{2}\right)$ of $\mathrm{Pb}$ (II) may promote the proton transfer ${ }^{31,32}$ contributing to its outstanding catalytic performances. These features may explain why $\mathrm{Pb}(\mathrm{II})$ demonstrates better catalytic performances for the formation of lactic acid than many other metal ions (Fig. 1).

Our computational studies further suggest that the $\mathrm{Pb}$ (II)-OH species in the aqueous solution may primarily contribute to catalysing the isomerization of glucose to fructose and that of the trioses to lactic acid via the 1,2-hydride shift mechanism. We have experimentally demonstrated the generation of $\mathrm{Pb}(\mathrm{II})-\mathrm{OH}$ in the $\mathrm{Pb}$ (II) aqueous solution. Future experimental studies are needed to clarify the interaction of the $\mathrm{Pb}(\mathrm{II})-\mathrm{OH}$ species with the substrate under reaction conditions. In addition to $\mathrm{Pb}(\mathrm{II})$ and $\mathrm{Pb}(\mathrm{II})-\mathrm{OH}$ species, water molecules and the reversibly generated protons in hot water also have roles in some of the steps. Furthermore, lactic acid autocatalyzes the hydrolysis of microcrystalline cellulose. It is encouraging that simple $\mathrm{Pb}(\mathrm{II})$ in combination with water can accomplish such complicated cascade reactions.

It is important to note that the toxicity of $\mathrm{Pb}$ (II) should be considered before the practical application of the present catalytic system for the production of lactic acid from cellulose. We have demonstrated that $\mathrm{Pb}$ (II) can be separated and recovered by using a cationic exchanging resin, but the separation and recovery of $\mathrm{Pb}$ (II) would increase the process cost. In addition, because of the difficulties in separating lactic acid from the aqueous solution containing the byproducts, including glucose, fructose and other organic acids, and its subsequent purification, the product selectivity should be further improved. Nevertheless, the results and insights obtained in the current work are quite encouraging and can inspire further design of more environmental friendly and more efficient catalytic systems for the transformation of cellulose to lactic acid in water. As a first step, we have attempted to use the combination of dual or multiple cations for the conversion of glucose, because the most suitable catalysts for different steps in the cascade reactions for converting glucose to lactic acid may be different. Very recently, we found that a dualcation system, which was composed of $\mathrm{Al}(\mathrm{III})$ and $\mathrm{Sn}(\mathrm{II})$ with a molar ratio of $1 / 1$, provided a lactic acid yield of $81 \%$ from glucose after $2 \mathrm{~h}$ at $463 \mathrm{~K}$, which is a higher yield than that obtained with $\mathrm{Pb}(\mathrm{II})$ (71\%). The conversion of ball-milled cellulose with the $\mathrm{Al}(\mathrm{III})-\mathrm{Sn}(\mathrm{II})$ combination afforded a lactic acid yield of $66 \%$ after a reaction at $463 \mathrm{~K}$ for $4 \mathrm{~h}$, which is comparable to that obtained with $\mathrm{Pb}(\mathrm{II})$. Further improvements can be expected through clarification of the roles of the different catalytic components in each step of the cascade reactions from cellulose to lactic acid and further optimization of the dual- or multicomponent catalytic systems.

\footnotetext{
Methods

Materials and general methods. The microcrystalline cellulose was purchased from Alfa-Aesar. The chemicals primarily used in this work were as follows: D$(+)$-glucose (99.5\%, Alfa-Aesar), D-fructose (99\%, Alfa-Aesar) and $\mathrm{Pb}\left(\mathrm{NO}_{3}\right)_{2}$ (99\%, Alfa-Aesar). The ball-milled cellulose was obtained by ball-milling the purchased microcrystalline cellulose at 60 r.p.m. on a SFM-1 Desk-top planetary ball miller (MTI Corporation) for $48 \mathrm{~h}$. The crystallinity was estimated from the $\mathrm{X}$-ray diffraction patterns of the cellulose samples ${ }^{37}$. X-ray diffraction patterns were collected on a Panalytical X'pert Pro diffractometer using $\mathrm{Cu} \mathrm{K}_{\alpha}$ radiation $(40 \mathrm{kV}, 30 \mathrm{~mA})$. Fourier-transform ion cyclotron resonance mass spectrometry measurements were performed on a Bruker APEX IV 7.0T Fourier-transform ion
}

cyclotron resonance mass spectrometer in positive ion mode equipped with an external electrospray ionization source. $\mathrm{Pb}\left(\mathrm{NO}_{3}\right)_{2}$ was dissolved in water to obtain a concentration of $\sim 0.15 \mathrm{mmoll}^{-1}$. This solution was electrosprayed from a capillary biased at $4,400 \mathrm{~V}$. The scan range of $\mathrm{m} / \mathrm{z}$ was from 100 to 600 . An accuracy of $m / z$ of $1 \times 10^{-5}$ was achieved. ${ }^{1} \mathrm{H}$ NMR spectra were recorded on a Bruker Avance II $400 \mathrm{MHz}$ instrument operating at $400 \mathrm{MHz}$. All of the experiments were conducted in $\mathrm{D}_{2} \mathrm{O}$ with chemical shifts reported in parts per million downfield from sodium 3-(trimethylsilyl)-1-propanesulphonate (DSS). The tandem mass spectrometry measurements were performed on an Esquire 3000 Plus mass spectrometer equipped with an electrospray ionization source. The ionization was performed under normal electrospray conditions (flow rate: $4 \mu \mathrm{lmin}{ }^{-1}$, $4.5 \mathrm{kV}$, dry temperature: $493 \mathrm{~K}$ ). A collision energy between 0.2 and $0.8 V_{\mathrm{p}-\mathrm{p}}$ was employed for each collision-induced dissociation stage (in each case, the precursor beam attenuation was set between 0 and 10\%), and a mass range between 2 and 4 Da was isolated before the collision-induced dissociation experiment (the isolation width was increased with the number of multiple stage experiments to maintain as many ions as possible in the trap).

Catalytic reaction. The conversions of cellulose, hexose and triose intermediates, and other biomasses were performed in a batch-type Teflon-lined stainless-steel autoclave. For example, for the conversion of cellulose, the catalyst and the powdery cellulose sample were added to the reactor that had been pre-charged with $\mathrm{H}_{2} \mathrm{O}$. After the introduction of $\mathrm{N}_{2}$ at a pressure of $3 \mathrm{MPa}$, the reactor was placed in an oil bath. After the system reached the reaction temperature (typically $463 \mathrm{~K}$ ), the reaction was initiated by vigorous stirring. After a fixed time, the reaction was quickly terminated by cooling the reactor to room temperature in cold water. The liquid products were analysed by high-performance liquid chromatography (HPLC, Shimazu LC-20A) equipped with an RI detector and a Shodex SUGARSH-1011 column $\left(8 \times 300 \mathrm{~mm}^{2}\right)$ using a dilute $\mathrm{H}_{2} \mathrm{SO}_{4}$ aqueous solution as the mobile phase. The yields of the main products, such as lactic acid, glucose, fructose and HMF, are primarily displayed herein, and the details of the other byproducts are described in Supplementary Note S2. We performed the same experiment at least in triplicate for each run, and the relative error was $<3 \%$. The high-performance liquid chromatography quantification was further validated via a titration method ${ }^{38}$.

Theoretical computation. All of the calculations were performed with the Gaussian 09 software package. The geometries of all of the transition states, reactants and intermediates involved in the reaction were fully optimized using a hydrated cluster in conjunction with the continuum solvation model of SMD at the B3LYP/6-31G(d) level of theory (the LanL2DZ-ECP basis set was employed for $\mathrm{Pb}$ ). Harmonic frequency calculations were performed at the equilibrium geometries to confirm first-order saddle points and local minima on the potential energy surfaces, and to estimate the zero-point energy, as well as the thermal and entropic corrections, at $298.15 \mathrm{~K}$ and $1 \mathrm{~atm}$. The correlation between the stable structures and the transition states was verified by analysing the corresponding imaginary frequency mode, as well as by limited intrinsic reaction coordinate calculations The relative energies of the B3LYP/6-31G(d)-optimized structures were further refined by single-point calculations at the B3LYP/6-311 + $+\mathrm{G}(\mathrm{d}, \mathrm{p})$ level (the polarized LANL2DZdp ECP basis set was employed for $\mathrm{Pb}$ ) with inclusion of solvent effects. Natural bond orbital analyses at the B3LYP/6-311 $++\mathrm{G}(\mathrm{d}, \mathrm{p})$ level were performed to determine the atomic charge populations. For estimation of the Gibbs free energy, direct calculations in combination with frequency analysis in solution were performed, which has been verified to be a correct and practical approach $^{39}$ especially when liquid-phase and gas-phase structures differed significantly or when the stationary points present in the liquid solution could not survive in the gas phase. The B3LYP method was compared with several other popular density functional theoretical methods, including B3PW91, B97-D, M06, X3LYP and M06-2X, for the isomerization of glucose to its enol form, and B3LYP was found to be adequate for the present mechanistic study. In addition to $298.0 \mathrm{~K}$, thermal corrections were also assessed at $463.0 \mathrm{~K}$ to explore the temperature effect on the Gibbs free energy, and the temperature effect was not remarkable here.

\section{References}

1. Ragauskas, A. J. et al. The path forward for biofuels and biomaterials. Science 311, 484-489 (2006)

2. Clark, J. H. Chemistry goes green. Nat. Chem. 1, 12-13 (2009).

3. Román-Leshkov, Y., Chheda, J. N. \& Dumesic, J. A. Phase modifiers promote efficient production of hydroxymethylfurfural from fructose. Science 312, 1933-1937 (2006).

4. Zhao, H., Holladay, J. E., Brown, H. \& Zhang, Z. C. Metal chlorides in ionic liquid solvents convert sugars to 5-hydroxymethylfurfural. Science 316, 1597-1600 (2007).

5. Chheda, J. N., Huber, G. W. \& Dumesic, J. A. Liquid-phase catalytic processing of biomass-derived oxygenated hydrocarbons to fuels and chemicals. Angew. Chem. Int. Ed. 46, 7164-7183 (2007).

6. Binder, J. B. \& Raines, R. T. Simple chemical transformation of lignocellulosic biomass into furans for fuels and chemicals. J. Am. Chem. Soc. 131, 1979-1985 (2009). 
7. Dodds, D. R. \& Gross, R. A. Chemicals from biomass. Science 318, 1250-1251 (2007).

8. Holm, M. S., Saravanamurugan, S. \& Taarning, E. Conversion of sugars to lactic acid derivatives using heterogeneous zeotype catalysts. Science 328, 602-605 (2010)

9. de Clippel, F. et al. Fast and selective sugar conversion to alkyl lactate and lactic acid with bifunctional carbon-silica catalysts. J. Am. Chem. Soc. 134, 10089-10101 (2012).

10. Corma, A., Iborra, S. \& Velty, A. Chemical routes for the transformation of biomass into chemicals. Chem. Rev. 107, 2411-2502 (2007).

11. Dauenhauer, P. J., Dreyer, B. J., Degenstein, N. J. \& Schmidt, L. D. Millisecond reforming of solid biomass for sustainable fuels. Angew. Chem. Int. Ed. 46, 5864-5867 (2007).

12. Zhang, Y. P. \& Lynd, L. R. Toward an aggregated understanding of enzymatic hydrolysis of cellulose: noncomplexed cellulase systems. Biotechol. Bioeng. 88, 797-824 (2004)

13. Stark, A. Ionic liquids in the biorefinery: a critical assessment of their potential. Energy Environ. Sci. 4, 19-32 (2011)

14. Van de Vyver, S., Geboer, J., Jacobs, P. A. \& Sels, B. F. Recent advances in the catalytic conversion of cellulose. ChemCatChem. 3, 82-94 (2011)

15. Kobayashi, H., Ohta, H. \& Fukuoka, A. Conversion of lignocellulose into renewable chemicals by heterogeneous catalysis. Catal. Sci. Technol. 2, 869-883 (2012).

16. Fukuoka, A. \& Dhepe, P. L. Catalytic conversion of cellulose into sugar alcohols. Angew. Chem. Int. Ed. 45, 5161-5163 (2006).

17. Ji, N. et al. Direct catalytic conversion of cellulose into ethylene glycol using nickel-promoted tungsten carbide catalysts. Angew. Chem. Int. Ed. 47, 8510-8513 (2008).

18. Liu, Y., Luo, C. \& Liu, H. Tungsten trioxide promoted selective conversion of cellulose into propylene glycol and ethylene glycol on a ruthenium catalyst. Angew. Chem. Int. Ed. 51, 3249-3253 (2012).

19. Hayashi, Y. \& Sasaki, Y. Tin-catalyzed conversion of trioses to alkyl lactates in alcohol solution. Chem. Commun. 2716-2718 (2005).

20. Bicker, M., Endres, S., Ott, L. \& Vogel, H. Catalytic conversion of carbohydrates in subcritical water: a new chemical process for lactic acid production. J. Mol. Catal. A: Chem. 239, 151-157 (2005).

21. Dusselier, M., Wouwe, P., Dewaele, A., Makshina, E. \& Sels, B. Lactic acid as a platform chemical in the biobased economy: the role of chemocatalysis. Energy Environ. Sci. 6, 1415-1442 (2013).

22. Yan, X., Jin, F., Tohji, K., Kishita, A. \& Enomoto, H. Hydrothermal conversion of carbohydrate biomass to lactic acid. AIChE. J. 56, 2727-2733 (2010).

23. Nolen, S. A., Liotta, C. L., Eckert, C. A. \& Gläser, R. The catalytic opportunities of near-critical water: a benign medium for conventionally acid and base catalyzed condensations for organic synthesis. Green. Chem. 5, 663-669 (2003).

24. Luo, C., Wang, S. \& Liu, H. Cellulose conversion into polyols catalyzed by reversibly-formed acids and supported ruthenium clusters in hot water. Angew. Chem. Int. Ed. 46, 7636-7639 (2007).

25. Zakrzewska, M. E., Bogel-Łukasik, E. \& Bogel-Łukasik, R. Ionic liquid-mediated formation of 5-hydroxymethylfurfural-a promising biomass-derived building block. Chem. Rev. 111, 397-417 (2011).

26. Wang, B. J. \& Cao, Z. X. Hydration of carbonyl groups: the labile $\mathrm{H}_{3} \mathrm{O}^{+}$ion as an intermediate modulated by the surrounding water molecules. Angew. Chem. Int. Ed. 50, 3266-3270 (2011).

27. Sunoj, R. B. \& Anand, M. Microsolvated transition state models for improved insight into chemical properties and reaction mechanisms. Phys. Chem. Chem. Phys. 14, 12715-12736 (2012).

28. Assary, R. \& Curtiss, L. Comparison of sugar molecule decomposition through glucose and fructose: a high-level quantum chemical study. Energy Fuels 26, 1344-1352 (2011).
29. Assary, R. \& Curtiss, L. Theoretical study of 1,2-hydride shift associated with the isomerization of glyceraldehyde to dihydroxy acetone by lewis acid active site models. J. Phys. Chem. A 115, 8754-8760 (2011).

30. Román-Leshkov, Y., Moliner, M., Labinger, J. A. \& Davis, M. E. Mechanism of glucose isomerisation using a solid lewis acid catalyst in water. Angew. Chem. Int. Ed. 49, 8954-8957 (2010).

31. Akibo-Betts, G., Barran, P. F., Puskar, L., Duncombe, B., Cox, H. \& Stace, A. J. Stable $\left[\mathrm{Pb}(\mathrm{ROH})_{\mathrm{n}}\right]^{2+}$ complexes in the gas phase: softening the base to match the Lewis acid. J. Am. Chem. Soc. 124, 9257-9264 (2002).

32. Cox, H. \& Stace, A. J. Molecular view of the anomalous acidities of $\mathrm{Sn}^{2+}$, $\mathrm{Pb}^{2+}$, and $\mathrm{Hg}^{2+}$. J. Am. Chem. Soc. 126, 3939-3947 (2004).

33. McQuinn, K., Hof, F., McIndoe, J., Chen, X., Wu, G. \& Stace, A. J. Evidence of asymmetric cation solvation from the instability of $\left[\mathrm{Pb}\left(\mathrm{H}_{2} \mathrm{O}\right)_{n}\right]^{2+}$ complexes. Chem. Commun. 4088-4090 (2009).

34. Shi, T., Oriove, G., Guo, J., Bohme, D., Hopkinson, A. C. \& Siu, K. W. M. Existence of doubly charged lead monohydrate: experimental evidence and theoretical examination. J. Am. Chem. Soc. 126, 7975-7980 (2004).

35. Amster, I. J. Fourier transform mass spectrometry. J. Mass Spectrom. 31, 1325-1337 (1996).

36. Feng, X. \& Siegel, M. M. FTICR-MS applications for the structure determination of natural products. Anal. Bioanal. Chem. 389, 1341-1363 (2007).

37. Sasaki, M., Adschiri, T. \& Arai, K. Kinetics of cellulose conversion at $25 \mathrm{MPa}$ in sub- and supercritical water. AIChE. J. 50, 192-202 (2004).

38. Sharman, D. Determination of lactic acid and poly(lactic acid)s in a dermatological formulation by capillary electrophoresis. Analyst 122, 709-713 (1997).

39. Ribeiro, R. F., Marenich, A. V., Cramer, C. J. \& Truhlar, D. G. Use of solutionphase vibrational frequencies in continuum models for the free energy of solvation. J. Phys. Chem. B 115, 14556-14562 (2011).

\section{Acknowledgements}

This work was supported by the Natural Science Foundation of China (Nos. 21173172, 21103143, 21133007, 21033006 and 21161130522), the National Basic Research Program of China (No. 2013CB933100), and the Program for Changjiang Scholars and Innovative Research Team in Chinese Universities (No. IRT1036).

\section{Author contributions}

Y. (Yanliang) W. and W.D. performed most of the experiments and analysed the experimental data. B.W. and C.Z. conducted the theoretical computations. Q.Z. analysed the data and co-wrote the paper. X.W. and Z.T. performed some of the glucose and fructose conversion experiments. G.W. conducted a portion of the theoretical calculations and reviewed the manuscript. Y. (Ye) W. designed the study, analysed the experimental results and co-wrote the paper. Z.C. analysed the computational results and co-wrote the paper. H.W. reviewed the paper. All of the authors discussed the results and reviewed the manuscript.

\section{Additional information}

Supplementary information accompanies this paper at http://www.nature.com/ naturecommunications

Competing financial interests: The authors declare no competing financial interests.

Reprints and permission information is available online at http://npg.nature.com/ reprintsandpermissions/

How to cite this article: Wang, Y. et al. Chemical synthesis of lactic acid from cellulose catalysed by lead(II) ions in water. Nat. Commun. 4:2141 doi: $10.1038 /$ ncomms3141 (2013). 